\title{
Clinicopathological Profile of Breast Cancer Patients at a Tertiary Care Hospital in Marathwada Region of Westen India
}

\author{
Unmesh Vidyadhar Takalkar ${ }^{1 *}$, Shilpa Balaji Asegaonkar², Umesh Kulkarni', \\ Pushpa R Kodlikeri ${ }^{3}$, Ujwala Kulkarni ${ }^{4}$, Mamta Saraf ${ }^{5}$, Suresh Advani ${ }^{6}$
}

\begin{abstract}
Background: Breast cancer is the most prevalent malignancy among women with wide differences in clinical profile from region to region. The present study aimed to describe the profile of breast cancer patients attending a tertiary care hospital in Marathwada region of Western India. Materials and Methods: In this descriptive retrospective study, we reviewed records of pathologically diagnosed patients of breast cancer managed at our center from years 2009 to 2015 . Data with respect to demographic status, detailed past, medical, familial and personal history, findings of clinical examination and histological features were obtained. Patients were staged according to the Tumor Node Metastasis (TNM) system. Results: Among 260 cases, mean age of presentation was 52.6, with average age of menarche of 11.3 and menopause of 52.6 years. The majority of patients were from urban regions and were postmenopausal (64.3\%). Main clinical features presentation were breast lumps. Most patients were in stage II and had infiltrating duct carcinomas. Conclusions: Most common risk factors for breast cancer observed are increasing age, low parity and obesity. Breast cancer was more prevalent among postmenopausal women presenting in stage II with infiltating duct carcinoma in our region of India.
\end{abstract}

Keywords: Breast cancer - clinical profile - Marathwada region - India

Asian Pac J Cancer Prev, 17 (4), 2195-2198

\section{Introduction}

Breast cancer is the second most common malignancy among Indian women accounting for $7 \%$ of global burden of breast cancer (Ferlay et al, 2012). With the rapid evolution in socioeconomic status and lifestyle, epidemic of breast cancer is growing worldwide imposing huge burden on healthcare system. Till the year 2020, there could be rise by $50 \%$ in cancer rates to 15 millions (Pal et al, 2004). At present every year new 75000 cases are diagnosed in India (Chopra , 2001). It has been predicted that over 90000 new cases will be added and 50000 women will die of annually in India. Its incidence is three times more in urban area in comparison with that of rural area (Boyle, 2010). There might be considerable variations in risk factors and presentation of the disease regionwise.

Number of studies have been published with respect to clinical and pathological profiles of breast cancer patients from India. But limited data has been presented in literature from our Marathwada region which is located in of Maharashtra, a part of western India. Present study aimed to evaluate demographic profile, risk factors, clinical presentation, pathological features of breast cancer patients diagnosed and managed at our tertiary care hospital.

\section{Materials and Methods}

Present retrospective study was conducted at United CIIGMA Hospital which is a tertiary care center catering health services to cancer patients from urban and rural ares of Marathwada and adjoining regions. This study was feasible because our hospital has surgical as well as medical oncology and radiotherapy unit. With the approval of Institutional Ethics Committee and permission from Chief Medical Director, we reviewed record of pathologically diagnosed and managed patients of breast cancer from year 2009 to 2015 . In detail data of 330 patients was retrieved from the medical record section of hospital in the approved protocol. Out of these, 55 patients were with missing data, hence were excluded. We recorded demographic and clinicopathological profile and treatment offered to the breast cancer patients. Staging of the breast tumor was done according to Tumor Node Metastasis (TNM) classification.

Statistical analysis

After extracting necessary record, data was compiled in the microsoft excel. Desciptive analysis of baseline demographic, clinical and pathological charactristics was performed. 
Table 1.Demographic and baseline presentation of study participants

\begin{tabular}{|c|c|c|}
\hline Variables & $\begin{array}{l}\text { Number of cases } \\
(\text { Total } n=260 \text { ) }\end{array}$ & $\begin{array}{c}\text { Percentage } \\
(\%)\end{array}$ \\
\hline \multicolumn{3}{|l|}{ Sex } \\
\hline Male & 5 & \\
\hline Female & 260 & \\
\hline Age (Mean) years & $52.6+/-10.5$ & \\
\hline Range & $28-85$ years & \\
\hline \multicolumn{3}{|l|}{ Family History- } \\
\hline Yes & 4 & \\
\hline \multicolumn{3}{|l|}{$1.5 \%$} \\
\hline No & 256 & $98.5 \%$ \\
\hline Positive History of HRT/OCP- & 35 & $13.40 \%$ \\
\hline \multicolumn{3}{|l|}{ Habits } \\
\hline Tobacco & 9 & $3.46 \%$ \\
\hline Alcoholic & None & \\
\hline Smoking & None & \\
\hline Menstrual Status- premenopausa & 93 & $35.7 \%$ \\
\hline Menopause & 167 & $64.3 \%$ \\
\hline Residency- urban & 239 & $93.5 \%$ \\
\hline rural & 21 & $6.5 \%$ \\
\hline $\operatorname{BMI}\left(\mathrm{Kg} / \mathrm{m}^{2}\right)$ & $26.45+/-3.21$ & \\
\hline Age at menarche & $11.32+/ 1.7$ & \\
\hline Age at first pregnancy (Mean) & $18.6+/-4.2$ & \\
\hline \multicolumn{3}{|c|}{ Parity- } \\
\hline 0 & 18 & $6.92 \%$ \\
\hline $1-2$ & 134 & $51.53 \%$ \\
\hline $2-3$ & 72 & $27.69 \%$ \\
\hline $3-4$ & 33 & $12.69 \%$ \\
\hline 5 and above & 3 & $1.15 \%$ \\
\hline Mean Age at menopause & $52.6+/-3.4$ & \\
\hline Past history of breast biopsy & 4 & $1.50 \%$ \\
\hline
\end{tabular}

\section{Results}

During last 5 years, total 265 patients were diagnosed as breast cancer pathologically and managed. Demographic and clinical characteristics of the patients are demonstrated in Table 1.

Among patients with complete data, 5 were male and 260 were famales. Being referral center in city, most of our patients $(n=239)$ were from urban area. Age group of our patient was 28 to 85 years with mean age of $52.6+/$ 10.5 years. Mean age at menarche was $11.32+/ 1.7$ years ranging from 10 to 15 years. Age at the time of first child birth was $18.6+/-4.2$ years ranging from 16 to 25 years. Positive family history in first and second degree relatives was present only in $1.5 \%(n=4)$ cases. There were 18 nulliparous women (\%)with breast cancer.

With respect to menstrual status, the prevalence of breast cancer was more in postmenopausal women compared to premenopausal $(64.3 \%$ Vs $35.7 \%)$. Mean Body Mass Index (BMI) of the cases was 26.45+/-3.21. There was no history of smoking and alcoholism, but 9 women were tobacco chewers. 35 women were taking either orel cotraceptive pills in the past or hormone replacement therapy. Past history of breast biopsy or benign lesions was present only in 4 patients. 11 patients had underwent hysterectomy in past for nonmalignant gynaecological reasons.

Table 2 decipits the clinical presentation of breast cancer
Table 2. Distribution of Clinical and Histological Presentation of Breast Cancer Patients

\begin{tabular}{lrr}
\hline Characteristics & Number of patients & Percentage \\
\hline Symptoms & 260 & \\
Lump in breast & 13 & $100 \%$ \\
Lump with pain & 1 & $5 \%$ \\
lump, nipple discharge & 128 & $0.38 \%$ \\
Site of lump & 132 & $49.23 \%$ \\
Left breast & & $50.77 \%$ \\
Histopathology & 258 & \\
Infiltrating duct & & $99.24 \%$ \\
carcinoma & 1 & \\
Paget's disease & 1 & $0.38 \%$ \\
Medullary carcinoma & & $0.38 \%$ \\
\hline
\end{tabular}

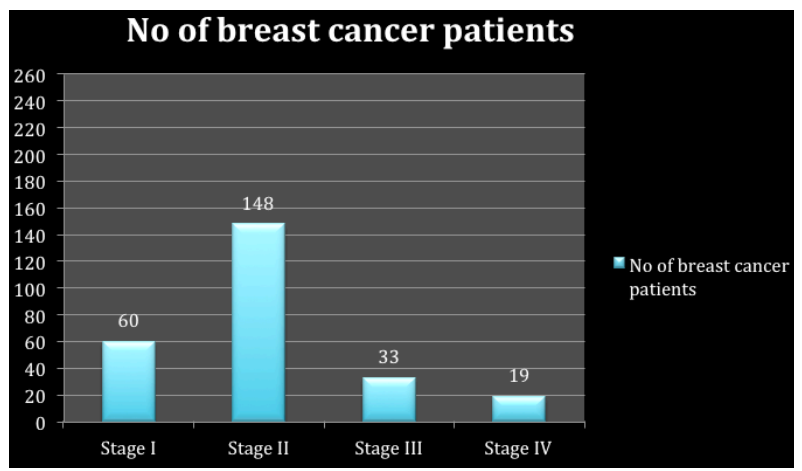

Figure 1. Stage-Wise Distribution of Breast Cancer Patients

patients at the time of diagnosis. Most predominating symptom at was lump in breast among all the patinets. In $5 \%$ patients it was associated with pain while nipple discharge was present only in one patient. As far as the site is taken into consideration, both right as well as left side involved equally with slight difference $(49.23 \% \mathrm{Vs}$ $50.77 \%$ ). After reviewing histological reports, except 2 remaining all 258 had infiltrating duct carcinoma (IDC). Paget's disease was present in one woman and one had medullary carcinoma. Most of the patients had grade II tumors followed by grade I and III.

Following graph shows stagewise distribution of breast cancer patients according to TNM classification. Out of 260cases, $23.07 \%$ were in stage I, $56.92 \%$ in stage II, $12.69 \%$ in stage III and $7.3 \%$ in stage IV. Following graph represents stagewise distribution of yhe patients.

\section{Discussion}

In the present descriptive retrospective study we analyzed institutional data of last 5 years in breast cancer patients with regard to baseline demographic, clinical and pathological profile. Data from clinical practice concerning profile of breast malignancy is limited from our region. Hence we intended to study the status of breast cancer patients including risk factors, clinical and pathologicl profile.

Age- consolidated report of the HBCRs (2007-2011) stated that $65 \%$ to $70 \%$ of women with breast cancer were 
above 50 years of age and only $30-35 \%$ were below 50 years. But now prevalence is rising in younger women also (Imran, 2011). Our analysis show that frequency of breast cancer is shifted to fifth and sixth decade age group. Our majority of the patients $(68 \%)$ were in the age group of 45 to 60 years. Youngest patient was 28 and oldest was 85 years old. In India, incidence of breast cancer is rising nowadays from thirties with peak at 5064 years of age (National Cancer Registry Programme 2001). We observed similar pattern of age distribution at our region. RA Badve et al, in their study on hormone receptor expression in 2001 breast cancer patients mean age of the patients was 49 years ranging from 20 to 99 years (Badwe et al, 2011). Parity ranged from 0 to 8,18 were nulliparous which is a known risk factor for breast cancer. Breast feeding was practiced by $85.6 \%$ patients with duration rage from 3 months to 2 years.

Findings from north Indian population showed mean year $47.39+/-10.90$ in female and $56.5+/-7.77$ for male breast cancers and $65.8 \%$ patients were below 50 years of age (Sandhu DS et al, 2011). Raina and associates reported median age of 47 years in their patients with equal distrubution of premenopausal and postmenopausal status (Raina V et al, 2005). Menstrual status analysis in our study showed $64.3 \%$ breast cancer women attained menopause while $35.7 \%$ were premenopausal group. This signifies rising risk of breast cancer with increasing age in postmenopausal women. In concern with distribution of risk factors, our findings supports observations of previous reports (Balsubramaniam,.In Western countries breast cancer is more prevalent in women in fifth and sixth decade of life (Anderson et al, 2002).

Our patients presented with lump in breast as the commonest clinical feature in all patients. Site of lump were almost equally in right and left breast in upper outer quadrant. Out of 260 patients, $65 \%$ had history of duration of symptoms for more than 3 months. Early breast cancer may not be noticed due to lack of symptoms. But when tumor grows in size, patients presents with lump or swelling of breast with pain, dimpling, ulceration of skin, redness of nipple or skin, changed contour and texture of breast, discharge from nipple.

Stagewise analysis (TNM) of our patients supports findings of Raina et al. In comparison with western countries, Indian women present in stage III and IV (Deo et al). One of the study from Maharashtra found $71.35 \%$ women presenting in late stage at the time of diagnosis of breast cancer (Mohite et al, 2015). Similar observations were noted by studies from north and south Indian populations also (Suresh et al., 2013; Kokiwar, 2011; Hiremath et al., 2012; Agrawal, 2012). Badwe et al. (2011) observed maximum cases with grade III tumor (75.4\%) and invasive breast cancer(95.4\%).

Breast cancer is a multifactorial disease caused by complex interplay of genetic, hormonal and environmental factors. It is the second leading cause of cancer related death among women next to lung cancer. A survey conducted by ICMR in metropolitan cities of India observed double incidence of breast cancer from 1982 to 2005 . Every year around 100,000 new patients of breast cancer are added in India (Ali et al, 2011). Incidence of breast cancer is rising at fast pace because of rising prevalence of risk factors due to westernization of lifestyle. Increasing age is one of the most important risk factor. High calorie diet with lack of physical activity, altered reproductive pattern, early menarche and late menopause and decreased parity are highly prevalent risk factors for breast cancer. In our study, increasing age, postmenopausal status are the most frequent risk factors.

Our hospital is a referral center that provides ultramodern diagnostic and therpaeutic services to urban as well as rural patients from neighbouring areas under one roof. Breast cancer, a highly prevalent disease is a big threat to women's health, inspite of advanced diagnostic and therapeutic modalities. In India, there are remarkable differences in the incidence rates of breast cancer in metropolitan, urban and rural areas. According to National Cancer Incidence Programme (NCRP) data, incidence rate for breast cancer in metrocities Mumbai and Chennai was 33 and 32.1 per 1,00,000 respectively, while in urbal area of Pune and Bhopal 24.4 and 25.5 and 7.7 and 15.0 per 100,000 in rural areas of Barshi (Yeole, Kurkure, 2003). On extensive search for available literature, scarse data with respect to clinical profile of the patients from our area of Marathwada is available. So the study was undetaken to document the profile of cohort of breast cancer patients by retrospective descriptive analysis.

Limitations of the study: Hospital based obserational study, so may not represent underlying general population.

Data from the present study suggests high incidence of breast breast cancer in postmenopausal women. Most prevalent risk factors in our region are increasing age, early menarche, late menopause and obesity. Main clinical presentation is lump in breast in stage II of the disease. Most frequent histological type is infiltrating duct carcinoma.

\section{References}

Agrawal KH, Rajderkar SS (2012). Clinico-epidemiological profile of female breast cancers and its important correlates: a hospital based study. Natl J Comm Med, 3, 316.

Ali I, Wani WA, Saleem K (2011). Cancer scenario in India with future perspectives. Cancer Therapy, 8, 56-70,

Anderson WF, Chatterjee N, Ershler WB, Brawley OW (2002). Estrogen receptor breast cancer phenotypes in the Surveillance, Epidemiology, and End Results database. Breast Cancer Res Treat, 76, 27-36.

Badwe RA, Desai S, Ghosh J, et al (2011), progesterone and HER2 receptor expression in breast tumors of patients, and their usage of HER2-targeted therapy, in a tertiary care centre in India. Indian J Cancer, 48, 391-396.

Boyle P, Howell A (2010). The globalisation of breast cancer. Breast Cancer Res, 12, 7.

Chopra R (2001). The Indian scene. J Clin Oncol, 19, 106-11.

Deo SV, Samaiya A, Shukla NK, et al (2005). Breast conservation therapy for breast cancer: patient profile and treatment outcome at a tertiary care cancer center. Natl Med J India, 18, 178-181.

Ferlay J, Soerjomataram I, Ervik M, et al (2013) GLOBOCAN 2012 vl.0, Cancer incidence and mortality worldwide: IARC CancerBase No.11 (Internet). Lyon, France: International Agency for Research on Cancer; 2013. Available from: http://globocan.iarc.fr. 
Unmesh Vidyadhar Takalkar et al

Hiremath BSV, Kulkarni SS, Hallikeri UR, Patil BR, Gai PB (2012). Decade of breast cancer-trends in patients profiles attending tertiary cancer care center in South India. Asian J Epidemiol, 5, 103- 13.

Kokiwar PR, Kumar HB, Mubashare A (2011). Epidemiological and clinical profile of breast cancer patients at a tertiary care hospital in South India. J Cancer Res Theraput, 7, 95.

Mohite RV, Mohite VR (2015). Socio-demographic and clinical profile of women with breast cancer: a cross sectional study from western Maharashtra, India. Int J Health Sci Res, 5 , 44-8.

National Cancer Registry Programme (2001). Consolidated report of the population based cancer registries 1990-1996. New Delhi: Indian Council Medical Research.

Pal SK, Mittal B (2004). Improving cancer care in India: Prospects and challenges. Asian Pac J Cancer Prev, 5, 226-8.

Raina V, Bhutani M, Bedi R, et al (2005). Clinical features and prognostic factors of early breast cancer at a major cancer center in North India. Indian J Cancer, 42, 40-5.

Sandhu DS, Sandhu S, Karwasra RK, Marwah S (2010). Profile of breast cancer patients at a tertiary care hospital in north India. Indian J Cancer, 47.

Suresh P, Batra U, Doval DC (2013). Epidemiological and clinical profile of triple negative breast cancer at a cancer hospital in North India. Indian J Med Paediatr Oncol, 34, 89-95.

Yeole BB, Kurkure AP (2003). An epidemiological assessment of increasing incidence and trends in breast cancer in Mumbai and other sites in India, during the last two decades. Asian Pac J Cancer Prev, 4, 51-6. 